\title{
Uterine artery pulsatility index less than 1.0 as an isolated marker in predicting low-risk subjects for preeclampsia
}

\author{
Pankaj Desai $^{1 *}$, Meera Desai ${ }^{2}$ \\ ${ }^{1}$ Consultant, Obstetrics and Gynaecology Specialist, Janani Maternity Hospital, Baroda, India; Dean (Students), \\ Associate Professor and Unit Chief, Department of Obstetrics and Gynaecology, Medical College Baroda, India (VRS) \\ ${ }^{2}$ Consultant, Obstetrics and Gynaecology Specialist, Janani Maternity Hospital, Baroda, India
}

Received: 17 March 2016

Accepted: 12 April 2016

\author{
*Correspondence: \\ Dr. Pankaj Desai, \\ E-mail: drpankajdesai@gmail.com
}

Copyright: $\odot$ the author(s), publisher and licensee Medip Academy. This is an open-access article distributed under the terms of the Creative Commons Attribution Non-Commercial License, which permits unrestricted non-commercial use, distribution, and reproduction in any medium, provided the original work is properly cited.

\begin{abstract}
Background: Preeclampsia is one of the major obstetric vasculopathies. As the treatment of the cause of preeclampsia remains elusive, its prediction is much sought after. In this study the authors have tried to evaluate a relatively unstudied parameter of PI $<1.0$ in prediction of low-risk subjects for preeclampsia.

Methods: Subjects enrolled for the study were prospectively and longitudinally studied clinically and through colour Doppler for changes in values I-trimester and II-trimester of pregnancy. The techniques used were as described by Clinical Standards Committee. First uterine artery scan was obtained between 11 to 14 weeks of pregnancy (ITrimester scan). Second scan of the same woman was obtained between 20-22 weeks of pregnancy (II-Trimester scan). All such enrolled subjects were serially followed up to delivery and their obstetric outcome noted especially for development of preeclampsia. Data was carefully recorded and analysed using online statistical software.

Results: It was found that those subjects who had PI $<1$ in II-trimester, have a significantly less chances of developing PIH (P value being $<0.05$ ). But when PI $<1.0$ in I-trimester was analysed; it was found that the difference between those who developed PIH and those who did not was not statistically significant. Nevertheless, PI $<1.0$ in I-trimester had an excellent specificity and positive predictive value.

Conclusions: Pulsatility Index if $<1.0$ in II-trimester in any pregnant woman on colour Doppler indicates a low-risk subject for preeclampsia. In such subjects preventive medications like aspirin or aspirin + heparin combination can be safely stopped.
\end{abstract}

Keywords: Preeclampsia, Obstetric Vasculopathies, Doppler, Pulsatility Index

\section{INTRODUCTION}

Obstetric vasculopathies are all those obstetric conditions that have a placental vascular origin. These include recurrent spontaneous missed miscarriages of late I trimester and early II trimester, preeclampsia, IUGR, Recurrent Still-births and accidental haemorrhage. ${ }^{1}$ It is now well accepted that all these conditions have an immunological basis. Preeclampsia is one of the major obstetric vasculopathies. As the treatment of the cause of these conditions remains elusive, its prediction is much sought after. Vasculopathy being a disease of the vasculature it is very logical to study the changes in vascular flow for researching these conditions. In recent times, uterine artery Doppler changes are the most studied in obstetric vasculopathies.

There are many tests, clinical, biochemical as well as in imaging technology which have been tested and used for predicting high-risk subjects for preeclampsia and other obstetric vasculopathies. Nevertheless, identifying lowrisk subjects is equally useful if not more. In this prospective study the authors have tried to evaluate a relatively unstudied parameter of $\mathrm{PI}<1.0$ in prediction of low-risk subjects for preeclampsia. 
The complete and competent II wave of trophoblastic invasion is very important for preventing a vasculopathy in any pregnant woman. It results in reduction of resistance to vascular flow in the placental vascular bed. ${ }^{2}$ This gets reflected in changes in uterine artery colour Doppler. Diastolic Notch (DN) which is present in the uterine artery wave forms in early first trimester progressively reduces in depth and subsequently disappears as this second wave of trophoblastic invasion completes competently. $^{3}$

Pulsatility Index (PI) is a good index to study the resistance to the downstream blood flow. In this study we have tried to study the competence of Pulsatility Index (PI) in predicting preeclampsia.

\section{METHODS}

This is a diligently performed long drawn study commencing from the first enrolment at I-Trimester scan and longitudinally lasting right up to the obstetric performance of the enrolled woman. Subjects registered for the study were prospectively and longitudinally studied clinically and through colour Doppler for changes in values I-trimester and II-Trimester of pregnancy. Only those subjects with singleton pregnancies who could be subjected to both the scans and could then after be followed up right up to delivery were retained for the study.

Colour Doppler was done by the same observer (PD) from 2008 to 2015 with GELOGIQ P5 and from 2014 by GELOGIQ F8 ultrasound machine. The techniques used were as described by clinical standards committee. ${ }^{4}$ Using Doppler ultrasound, the main branch of the uterine artery is easily located at the cervicocorporeal junction, with the help of real-time colour imaging. Doppler velocimetry measurements are usually performed near to this location, either transabdominally or transvaginally by standard and well established methods described below. ${ }^{5-8}$

\section{First-trimester uterine artery evaluation:}

- Transvaginal technique: Transvaginally, the probe was placed in the anterior fornix. Similar to the transabdominal technique, the probe was moved laterally to visualize the paracervical vascular plexus, and the above steps were carried out in the same sequence as for the transabdominal technique.

- Transabdominal technique: a midsagittal section of the uterus was obtained and the cervical canal was identified. The probe was then moved laterally until the paracervical vascular plexus was seen. Colour Doppler was then turned on and the uterine artery was identified as it turns cranially to make its ascent to the uterine body. Measurements were taken at this point, before the uterine artery branched into the arcuate arteries. The same process is repeated on the contralateral side.
Second-trimester uterine artery evaluation (Only transabdominal technique used):

- The probe was placed longitudinally in the lower lateral quadrant of the abdomen, angled medially. Colour flow mapping was useful to identify the uterine artery as it was seen crossing the external iliac artery. The sample volume was placed $1 \mathrm{~cm}$ downstream from this crossover point. In a small proportion of cases if the uterine artery branched before the intersection of the external iliac artery, the sample volume was placed on the artery just before the uterine artery bifurcation. The same process was repeated for the contralateral uterine artery.

First scan was obtained between 11 to 14 weeks of pregnancy (I-Trimester scan). Second scan was obtained between 20-22 weeks of pregnancy (II-Trimester scan). PI was calculated as: (peak systolic velocity - end diastolic velocity) / time averaged velocity $=(P S V-E D V)$ /TAV. Expectedly PI undergoes changes as the resistance to blood flow in the placental bed reduces with advancing pregnancy.

All enrolled subjects were serially followed up to delivery and their obstetric outcome noted especially for development of preeclampsia. Those subjects who missed any one of the scans were dropped from the study. Also, those subjects whose obstetric outcome could not be recorded for whatever reason were dropped from the study.

Data thus obtained was carefully recorded and analysed using online statistical software. These results so obtained were examined in light of available references.

\section{RESULTS}

\section{Analysis of PI<1.0 in II-trimester}

Table 1: $\mathrm{PI}<1$ in II trimester and development of PIH.

\begin{tabular}{|lll|}
\hline & No PIH & PIH \\
\hline PI $<1.0$ & 55 & 11 \\
\hline PI $>1.0$ & 27 & 15 \\
\hline
\end{tabular}

Significant at $\mathrm{P}<0.05$, Sensitivity $67.07 \%$, Specificity $57.69 \%$.

In all there were 108 subjects in this group. As shown in Table I there were 66 subjects who had PI<1.0 in ITrimester. Of these 66, 55 did not develop PIH and 11 developed PIH. All these subjects were matched against those who had PI>1.0. There were 42 subjects during the same study period in whom PI>1.0. Of these 15 developed PIH and 27 did not develop PIH. These results were subjected to statistical analysis. It was found that those subjects who had $\mathrm{PI}<1$ have a significantly less chances of developing PIH ( $\mathrm{P}$ value being $<0.05$ ). In other words, these are low-risk subjects for preeclampsia. 


\section{Analysis of $P I<1.0$ in II-trimester}

Table 2: PI < 1 in I trimester and development of PIH.

\begin{tabular}{|lll|}
\hline & NO PIH & PIH \\
\hline PI $<1.0$ & 36 & 4 \\
\hline PI $>1.0$ & 239 & 56 \\
\hline
\end{tabular}

Chi-Square value: $1.933, \mathrm{P}$ value: 0.164 Not Significant

However when PI $<1.0$ in I-Trimester was analysed, it was found that the difference between those who developed PIH and those who did not was not statistically significant as shown in Table II. The authors acknowledge the limitation of statistical analysis as the number of women in one of the sub-groups is small. When the tests for sensitivity specificity were applied to these findings, the results are as shown in Table III.

\section{Table 3: Further analysis of PI $<1$ in I trimester and development of PIH.}

\begin{tabular}{|lll|}
\hline Parameter & Result & $95 \%$ CI \\
\hline Sensitivity & $13.09 \%$ & $9.34 \%$ to $17.66 \%$ \\
\hline Specificity & $93.33 \%$ & $83.80 \%$ to $98.15 \%$ \\
\hline Positive predictive value & $90.00 \%$ & $76.34 \%$ to $97.21 \%$ \\
\hline Negative predictive value & $18.98 \%$ & $14.67 \%$ to $23.93 \%$ \\
\hline
\end{tabular}

$\mathrm{PI}<1.0$ in I-trimester has a poor sensitivity and negative predictive value. But its specificity and positive predictive values are good. This means that if PI is $<1.0$ in I-trimester may not be good enough for identifying women who have a high-risk of developing in ITrimester. But it appears to be competent in prediction of low-risk of preeclampsia (limitation of this statistical interpretation is accepted).

\section{DISCUSSION}

Prediction of PIH remains a big challenge confronting obstetricians in clinical practice. Obstetric vasculopathies are obstetric conditions that have a placental-vascular origin. They have an immunological basis ${ }^{1}$. In occurrence of late vasculopathies like preeclampsia, failure of competent completion of second wave of trophoblastic invasion seems to play a key role. If the second wave of trophoblastic invasion is complete, the placenta successfully gets converted into a low vascular resistance bed. This gets reflected in reduction of indices of vascular resistance on colour Doppler in the critical uterine arteries. Pulsatility Index (PI) is one such index.

It is proved to be the most discriminative abnormal uterine artery Doppler parameter for predicting both early preeclampsia and early preterm birth. ${ }^{8}$ In this study we have tried to prospectively study the competence of changes in PI values on colour Doppler to predict preeclampsia and interesting results emerge.
$\mathrm{PI}>1.7$ in $\mathrm{II}-$ Trimester is considered as having a good value for prediction of high-risk subjects for preeclampsia. $^{9}$ For identifying low-risk subjects, we tested PI 1.0 based on a study by Yu CK et al. ${ }^{10}$

In II-Trimester, $\mathrm{PI}<1.0$ proved to be successful in identifying low-risk subjects for preeclampsia. Significant number of subjects did not develop preeclampsia if their PI was less than 1.0. As a clinical extension to this finding, one can say that if in any pregnant woman if $\mathrm{PI}<1.0$ in II trimester, the clinician can safely stop any preventive measures like aspirin or aspirin + heparin combination if being given for preventing obstetric vasculopathies.

In I-trimester however different results emerge. The specificity of $\mathrm{PI}<1.0$ in identifying women at a low-risk of developing preeclampsia in I-trimester is high $(93.33 \%$ with $83.80 \%$ to $98.15 \%$ at $95 \%$ CI). But its sensitivity was poor $(13.09 \%$ with $9.34 \%$ to $17.66 \%$ at $95 \% \mathrm{CI})$. In contrast another recent study found that as an isolated marker of future disease, its sensitivity in predicting preeclampsia and fetal growth restriction in low risk pregnant women is moderate, at $40-70 \%$. That study goes on to state that overall, first-trimester Doppler interrogation of the uterine artery performs better in the prediction of early-onset than late-onset preeclampsia. ${ }^{11}$

Interestingly when $\mathrm{X}^{2}$ test was applied to this data, difference was not found to be statistically significant. This opens the possibility that $\mathrm{PI}<1.0$ may not be useful as an isolated marker. But with added tests like biochemical markers or even USG parameters like Notch Depth Index (NDI) its efficiency may cross levels of statistical significance. $^{12}$

\section{CONCLUSION}

Pulsatility Index if $<1.0$ in II-trimester in any pregnant woman on colour Doppler indicates a low-risk subject for preeclampsia. In such subjects preventive medications like aspirin or aspirin + heparin combination can be safely stopped. However the same index alone may not be sufficient in predicting low-risk subjects for preeclampsia in I-trimester.

\section{Funding: No funding sources}

Conflict of interest: None declared

Ethical approval: The study was approved by the Institutional Ethics Committee

\section{REFERENCES}

1. Desai P. General Aspects of Obstetric Vasculopathies: Obstetric Vasculopathies: Jaypee Publishers: Delhi. 2013;1:3.

2. Pijnenborg R, Anthony J, Davey DA, Rees A, Tiltman A, Vercruysse L et al. Placental bed spiral arteries in the hypertensive disorders of pregnancy. BJOG. 1991;98(7)648-55. 
3. Papageorghiou AT, Yu CK, Bindra R, Pandis G, Nicolaides KH. Multicenter screening for preeclampsia and fetal growth restriction by transvaginal uterine artery Doppler at 23 weeks of gestation. Ultrasound in Obstetrics \& Gynecology. 2001;18(5)441-9.

4. Clinical Standards Committee: ISUOG Practice Guidelines: use of Doppler ultrasonography in obstetrics. Ultrasound Obstet Gynecol. 2013;41:2339.

5. Aquilina J, Barnett A, Thompson O, Harrington K. Comprehensive analysis of uterine artery flow velocity waveforms for the prediction of preeclampsia. Ultrasound Obstet Gynecol. 2000;16:16370.

6. Gomez O, Figueras F, Fernandez S, Bennasar M, Martinez JM, Puerto B, et al. Reference ranges for uterine artery mean pulsatility index at 11-41 weeks of gestation. Ultrasound Obstet Gynecol. 2008;32:128-32.

7. Jurkovic D, Jauniaux E, Kurjak A, Hustin J, Campbell S, Nicolaides KH. Transvaginal colour Doppler assessment of the uteroplacental circulation in early pregnancy. Obstet Gynecol. 1991;77:365-9.
8. Carter EB, Goetzinger K, Tuuli MG, Odibo L, Cahill AG, Macones GA et al. Evaluating the Optimal definition of abnormal first-trimester uterine artery doppler parameters to predict adverse pregnancy outcomes. J Ultrasound Med. 2015;34(7).

9. Plasencia W, Maiz N, Poon L, Yu C, Nicolaides KH. Uterine artery Doppler at $11+0$ to $13+6$ weeks and $21+0$ to $24+6$ weeks in the prediction of preeclampsia. Ultrasound Obstet Gynecol. 2008;32:13846.

10. Yu CK, Khouri O, Onwudiwe N, Spiliopoulos Y, Nicolaides KH. Prediction of pre-eclampsia by uterine artery Doppler imaging: relationship to gestational age at delivery and small-for-gestational age. Ultrasound Obstet Gynecol. 2008;31:310-313.

11. Khong SL, Kane SC, Brennecke SP, da Silva Costa F. First-trimester uterine artery Doppler analysis in the prediction of later pregnancy complications. Dis Markers. 2015; Article ID 679730.

12. Takahashi K, Ohkuchi A, Hirashima C, Matsubara S, Suzuki M. Establishing reference values for mean notch depth index, pulsatility index and resistance index in the uterine artery at 16-23 weeks gestation. J Obstet Gynaecol Res. 2012;38(11):1275-85.

Cite this article as: Desai $\mathrm{P}$, Desai $\mathrm{M}$. Uterine artery pulsatility index less than 1.0 as an isolated marker in predicting low-risk subjects for preeclampsia. Int J Reprod Contracept Obstet Gynecol 2016;5:1300-3. 